\title{
Uptake of Cerebroside, Cholesterol and Lecithin by Brain Myelin and Mitochondria
}

\author{
MILADA DOBIAŠOVÁ and NORMAN S. RADIN, Mental Health Research Institute, University of \\ Michigan, Ann Arbor, Michigan
}

\begin{abstract}
The uptake of emulsified labeled lipids by rat brain myelin and mitochondria was studied. Cerebroside and lecithin uptakes were greatly stimulated by addition of salts, particularly those containing divalent cations. Cholesterol uptake was not influenced by salts. Increasing concentrations of detergent (non-ionic) were inhibitory. Delipidated membranes took up much less lipid, but pretreatment with lecithin partially restored the ability to take up cerebroside and cholesterol. The lipid uptake appears to be nonenzymatic and appears to depend on the size of the emulsified particles. The possible role of such a phenomenon in membrane formation and maintenance is discussed.
\end{abstract}

\section{INTRODUCTION}

S ubcellular particles have been shown $\mathcal{S}$ to take up lipids and other substances by processes which seem to be nonenzymatic and which probably involve only the surface membrane. Such studies have been made with liver and adipose tissue mitochondria and microsomes, using labeled palmitate (1); brain particles, with gangliosides (2); liver mitochondria and plasma membranes, with steroids (3); and liver reticulosomes, using phospholipids (4). While not every one of these studies investigated the point, the uptakes appear to be adsorptive in nature. Whether the lipid molecules or micelles become attached at specific membrane sites is not known, nor is it clear whether the uptake is related to subsequent metabolic conversions or incorporation into specific substructures. In the case of uptake studies with partially delipidated mitochondria (5), the lipids apparently enter the original sites in the membranes.

In some cases, the lipid composition of membranes has been shown to change with time or under different environmental conditions. Brain myelin composition is different

IVisiting Scientist from the Isotope Laboratory, Institute for Biological Research, Czechoslovak Academy of Sriences, Prague. in young and older animals $(6,7)$, consistent with the observations that the fatty acid composition of brain lipids changes with age $(8,9)$. It is not evident from these studies whether only the recently formed membranes have differing composition, or whether all the membranes change with age.

The finding that subcellular particles can take up lipids raises the question as to whether this is not the normal process by which membranes are formed or maintained in the process of turnover. The possibility that membranes are self-assembling is supported by recent work from the Institute for Enzyme Research (10) and other laboratories.

The study described here has been made with the above questions in mind, using brain myelin. This particle was examined partly because of its metabolic inertness and partly because of its chemical simplicity. Brain mitochondria were also examined by way of comparison.

\section{MATERIALS AND METHODS}

\section{Myelin and Mitochondria}

A modification of the method of Autilio et al. (11) was used for the preparation of myelin. Rat brains weighing a total of about $7.5 \mathrm{~g}$ were homogenized in $30 \mathrm{ml}$ of $0.32 \mathrm{M}$ sucrose and the homogenate was filtered through cheesecloth. The filtrate was brought up to $52 \mathrm{ml}$ with the same sucrose solution, then layered over $0.656 \mathrm{M}$ sucrose in three 32 $\mathrm{ml}$ centrifuge tubes. Centrifugation in a swinging bucket rotor (SW 25.1) for $40 \mathrm{~min}$ at $40,000 \times \mathrm{g}$ yielded a dense interfacial layer which was diluted with an equal volume of water. The crude myelin suspension was purified by repetition of the layering step and final centrifugation in $0.25 \mathrm{M}$ sucrose (11). The myelin was then resuspended in $5 \mathrm{ml}$ of water.

The mitochondria were prepared from the particles sedimenting between $800 \times \mathrm{g}(10 \mathrm{~min})$ and $10,000 \times \mathrm{g}(15 \mathrm{~min})$, starting with a $10 \%$ homogenate in $0.25 \mathrm{M}$ sucrose. The crude mitochondria were suspended in $0.25 \mathrm{M}$ sucrose and layered over $0.9 \mathrm{M}$ sucrose. Centrifugation for $60 \mathrm{~min}$ at $100,000 \times \mathrm{g}$ yielded the mito- 
chondria in the pellet; these were suspended in $0.25 \mathrm{M}$ sucrose.

The myelin suspensions were stored no longer than 4 days, as cerebroside uptake was found to diminish after 6 days. The mitochondria, based on tests with cerebroside and cholesterol, were used within $24 \mathrm{hr}$.

The purity of the myelin and mitochondrial preparations was checked by analysis of their lipids (by TLC) and by enzymatic assays. The TLC plates showed the usual assortment of brain lipids, the cerebroside spots being particularly heavy in the myelin extract and the hydroxy cerebroside spot being barely visible in the mitochondrial extract. Also in semiquantitative agreement with published data for the lipid composition of these particles was the finding of relatively more cholesterol and less lecithin and ethanolamine lipids in myelin.

Assay of the myelin for acetylcholine esterase gave a specific activity of 0.6 units/ $\mathrm{mg}$ protein, to be compared with 4.8 units/mg in the $M_{1}$ (0.9) fraction of synaptic membranes (12). Mitochondrial contamination in the myelin was shown to be very low by assay of activity toward succinate with INT (iodonitrotetrazolium violet). The myelin contained 1.0 units $/ \mathrm{mg}$ protein, while purified mitochondria contained 13.5 units/mg (13). Microsomal contamination was estimated from the content of glutamine transferase: myelin activity was 2.8 units $/ \mathrm{mg}$ while the activity in purified microsomes was 31.4 units/mg (14). It is evident that the myelin, as with most subcellular preparations, was not completely pure; it should be noted that the experimental conditions of incubation resulted in additional purification. Moreover, it was found (see Results) that myelin and mitochondria were qualitatively the same with respect to lipid uptake.

\section{Incubation Conditions}

The lipid emulsions were prepared by adding solutions of lipid and detergent to chloroform, evaporating to dryness, then sonicating with water by means of a dipping probe for $2 \mathrm{~min}$. A Branson Sonifier was used; the entire lower part and vial were covered with a polyethylene bag to retain radioactive spray. The detergent used was G-2159, a polyoxyethylene stearate made by Atlas Chemical Industries, stored in chloroform. This detergent was found to be a superior emulsifier for lipids. Usually $20 \mu \mathrm{g}$ of cerebroside $+60 \mu \mathrm{g}$ of detergent, or 10 $\mu \mathrm{g}$ of cholesterol $+1 \mathrm{mg}$ of detergent were used in each incubation tube. The emulsions were stored no longer than 4 days. They exhibited a faint bluish tint in transmitted light.
Control tests under various incubation conditions, with and without the addition of absorbent cotton as trapping agent, showed no sedimentation of the emulsions under the conditions of assay.

Aliquots of salts, lipid emulsion $(0.4 \mathrm{ml})$ and particle suspension were added in total volume of $1 \mathrm{ml}$ to $15-\mathrm{ml}$ Corex centrifuge tubes. The suspensions were shaken gently 10 or $15 \mathrm{~min}$ at $37 \mathrm{C}$, then $4 \mathrm{ml}$ of cold $0.25 \mathrm{M}$ sucrose were added, the mixture was agitated, and the whole was centrifuged at $18,000 \times \mathrm{g}$ for $15 \mathrm{~min}$. The pelleted particles were suspended in $4 \mathrm{ml}$ of sucrose and centrifuged again. The pellet was suspended in $1 \mathrm{ml}$ of water and aliquots were taken for radioactivity and protein determination. Usually each incubation tube contained myelin or mitochondria equivalent to $600 \mu \mathrm{g}$ of protein.

The uptake of lipid was measured by adding 4 volumes of chloroform-methanol (2:1), centrifuging, and drying a part of the lower layer in a counting vial. The lipid was taken up in $10 \mathrm{ml}$ of a scintillation mixture based on toluene-ethanol $(95: 5)$. In the case of ${ }^{45} \mathrm{Ca}$, the pellet was suspended in $0.3 \mathrm{ml}$ of water and $5 \mathrm{ml}$ of XDC scintillation solvent (15) were added. The mixture was transferred to a counting vial with a 5-ml rinse of XDC.

\section{Reagents}

Stearoyl cerebroside labeled with tritium in the 6-position of the galactose was described previously (16). ${ }^{3} \mathrm{H}$-Cholesterol was obtained from Schwarz BioResearch, Inc., and was found to give a single radioactive spot on TLC with hexane-ether. "2P-Lecithin was prepared by incubation of labeled phosphate with liver slices (17). Radioautography of the product, after TLC with chloroform-methanol-water (24:7:1), showed a single radioactive spot. Carrier was added to produce compounds of the following specific activities: cerebroside and cholesterol $-2,000 \mathrm{cpm} / \mu \mathrm{g} ; \mathrm{CaC}_{2}-5,000$ $\mathrm{cpm} / \mu$ mole.

Egg yolk phospholipids (mainly lecithin and ethanolamine phosphoglycerides) were prepared by cellulose chromatography according to the method of Lea et al. (18). Lecithin was isolated from this preparation by silica gel chromatography. This was used to dilute the 32P-lecithin so as to give $4,000-6,000 \mathrm{cpm}$ per incubation.

\section{Other Methods}

Protein was determined by the method of Lowry et al. (19). Thin-layer chromatography was on Silica Gel G, using as visualization re- 


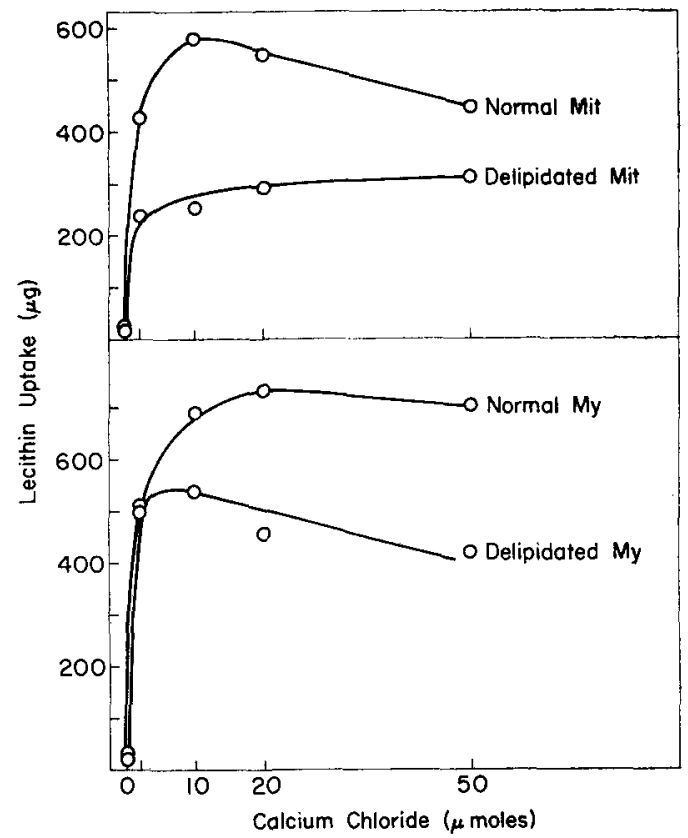

FIG. 1. Uptake of lecithin as a function of calcium ion concentration and delipidation. Incubations contain $1 \mathrm{mg}$ of labeled lecithin and particles equivalent to $0.6 \mathrm{mg}$ of protein, in a total volume of $1.2 \mathrm{ml}$. Upper curves: mitochondria. Lower curves: myelin.

agents, alkaline bromthymol blue, phosphomolybdic acid, or ninhydrin.

The delipidation procedure for the cell particles was based on the method of Lester and Fleischer (20). A suspension of particles containing $20-25 \mathrm{mg}$ protein in $2 \mathrm{ml}$ of water was added to $10 \mathrm{ml}$ of acetone and the mixture was stirred $5 \mathrm{~min}$. The solution was removed after centrifugation at $15,000 \times \mathrm{g}$ for $10 \mathrm{~min}$ and the particles were washed twice with $6 \mathrm{ml}$ of $0.25 \mathrm{M}$ sucrose, centrifuging as above. About $30 \%$ of the protein was lost from both particles by this procedure, and incubations were corrected for this so that equal weights of protein were in each incubation tube.

All materials were kept at $0-4 \mathrm{C}$ except where noted otherwise.

\section{RESULTS AND DISCUSSION}

\section{Effect of Salts}

The uptake of cerebroside by myelin was found to be greatly augmented by the presence of salts (Table I). Divalent ions were much more effective than monovalent ions, and little difference was seen between the members within each class. A linear relationship between up-

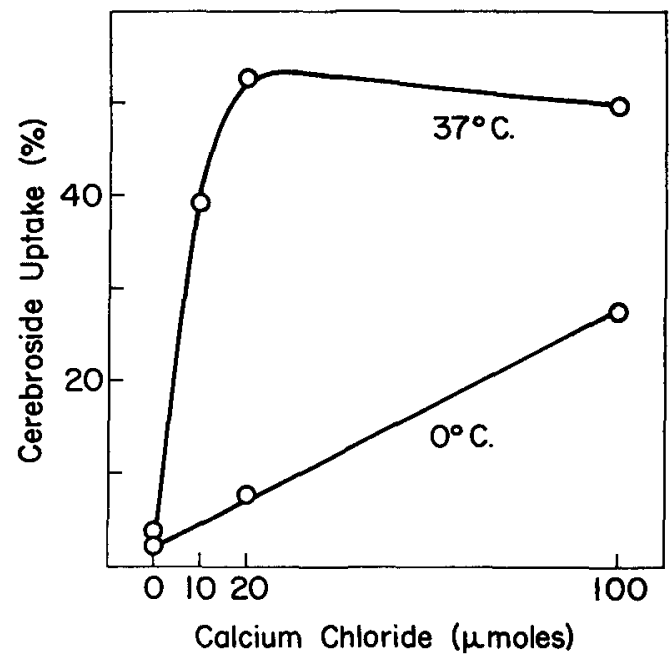

FIG. 2. Effect of $\mathrm{Ca}^{++}$concentration on cerebroside uptake by mitochondria. Tubes contained $1.2 \mathrm{mg}$ protein, $20 \mu \mathrm{g}$ cerebroside, and $40 \mu \mathrm{g}$ detergent.

take and monovalent ion concentration was seen up to $0.2 \mathrm{M}$; the divalent ions showed a rapidly increasing effect up to about $0.005 \mathrm{M}$ and a leveling off at about $0.02 \mathrm{M}$. Cholesterol uptake by myelin, on the other hand, was only slightly affected by salts. Without added salt, $42 \%$ of the cholesterol was taken up, while $46 \%$ was taken up in the presence of $5 \mu$ moles of $\mathrm{Ca}^{++}$.

Lecithin, like cerebroside, showed a marked dependence on salt concentration but differed in that there was some inhibition at higher $\mathrm{Ca}^{++}$concentrations (Fig. 1, upper curves). The inhibitory effect with myelin was some-

TABLE I

Effect of Salt Concentration on Cerebroside Uptake by Myelin

\begin{tabular}{|c|c|c|c|c|c|c|}
\hline $\begin{array}{c}\text { Amount of } \\
\text { cation } \\
\text { ( } \text { atoms) }\end{array}$ & $\mathrm{Ca}^{++}$ & $\mathbf{M g}^{++}$ & $\mathrm{Mn}^{++}$ & $\mathrm{Na}^{+}$ & $\mathbf{K}^{+}$ & $\mathbf{L i}^{+}$ \\
\hline $\begin{array}{r}0.5 \\
1 \\
2 \\
3 \\
4\end{array}$ & $\begin{array}{r}4 \\
6 \\
12 \\
19 \\
35\end{array}$ & $\begin{array}{l}4 \\
7\end{array}$ & $\begin{array}{r}6 \\
17\end{array}$ & 2 & 3 & 3 \\
\hline $\begin{array}{r}5 \\
10\end{array}$ & $\begin{array}{l}55 \\
64\end{array}$ & $\begin{array}{l}59 \\
63\end{array}$ & 59 & 3 & 3 & 3 \\
\hline $\begin{array}{l}20 \\
50\end{array}$ & $\begin{array}{l}76 \\
80\end{array}$ & $\begin{array}{l}81 \\
80\end{array}$ & $\begin{array}{l}84 \\
71\end{array}$ & $\begin{array}{r}6 \\
11\end{array}$ & $\begin{array}{r}7 \\
11\end{array}$ & $\begin{array}{r}6 \\
10\end{array}$ \\
\hline $\begin{array}{l}100 \\
200\end{array}$ & 80 & & & $\begin{array}{l}18 \\
20\end{array}$ & $\begin{array}{l}17 \\
23\end{array}$ & $\begin{array}{l}17 \\
21\end{array}$ \\
\hline
\end{tabular}

Incubation conditions: $20 \mu \mathrm{g}$ cerebroside and $40 \mu \mathrm{g}$ detergent; myelin equivalent to $700 \mu \mathrm{g}$ protein; cations present as chlorides. Some of the columns are averages of several experiments. Data are percent of cerebroside taken up by the particles. 
TABLE II

Uptake of Cerebroside and Cholesterol by Normal and Lipid-Depleted Myelin and Mitochondria as a Function of Calcium Concentration (Percent of Incubáted Sample)

\begin{tabular}{|c|c|c|c|c|c|}
\hline \multirow[b]{2}{*}{ Substrate } & \multirow{2}{*}{$\begin{array}{c}\text { Amount of } \\
\text { CaCl }_{2} \\
\text { ( } \mu \text { moles })\end{array}$} & \multicolumn{2}{|c|}{ Myelin } & \multicolumn{2}{|c|}{ Mitochondria } \\
\hline & & Normal & $\begin{array}{l}\text { Delipi- } \\
\text { dated }\end{array}$ & Normal & $\begin{array}{l}\text { Delipi- } \\
\text { dated }\end{array}$ \\
\hline $\begin{array}{l}\text { Cerebroside, } \\
20 \mu \mathrm{g}\end{array}$ & $\begin{array}{r}0 \\
2 \\
5 \\
10 \\
20 \\
50 \\
100\end{array}$ & $\begin{array}{r}7 \\
15 \\
44 \\
63 \\
61 \\
\ldots . . .\end{array}$ & $\begin{array}{r}5 \\
10 \\
17 \\
22 \\
\ldots \ldots . . \\
\ldots . . \\
\ldots . . .\end{array}$ & $\begin{array}{r}2 \\
\ldots . . \\
4 \\
8 \\
10 \\
17 \\
23\end{array}$ & 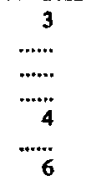 \\
\hline $\begin{array}{l}\text { Cholesterol, } \\
10^{\circ} \mu \mathrm{g}\end{array}$ & $\begin{array}{r}0 \\
10 \\
20 \\
100\end{array}$ & $\begin{array}{r}\ldots \ldots \\
39 \\
39\end{array}$ & $\begin{array}{r}\cdots \ldots \\
22 \\
22\end{array}$ & $\begin{array}{r}15 \\
\ldots \ldots \\
17 \\
\ldots \ldots . . .\end{array}$ & $\begin{array}{r}9 \\
9 \\
9\end{array}$ \\
\hline
\end{tabular}

Incubation conditions: With cerebroside, $40 \mu \mathrm{g}$ of detergent and membranes equivalent to $700 \mu \mathrm{g}$ of protein. With cholesterol, $1 \mathrm{mg}$ of detergent, myelin equivalent to 600 $\mu \mathrm{g}$ protein, mitochondria equivalent to $1 \mathrm{mg}$ protein. Total volume, $1 \mathrm{ml}$

what weaker than with mitochondria, but was reproducible.

Mitochondria resembled myelin in the need for ions in cerebroside uptake (Fig. 2). The $\mathrm{Ca}^{++}$dependency for cerebroside was seen at low temperature also, but the amount of uptake was less in the time interval studied.

As with myelin, mitochondrial uptake of cholesterol was little affected by $\mathrm{Ca}^{++}$. Mitochondria equivalent to $240 \mu \mathrm{g}$ of protein, under the usual conditions, took up $15 \%$ of the cholesterol without $\mathrm{Ca}^{++}$and $17 \%$ with $\mathrm{Ca}^{++}$.

A comparison of $\mathrm{MgSO}_{4}$ with $\mathrm{MgCl}_{2}$ (5 $\mu$ moles) for the effect on myelin uptake of cerebroside showed the anion to be unimportant here.

It is interesting that the uptake of both a non-ionic lipid (cerebroside) and a phospholipid was greatly influenced by salt concentration. In the case of the phospholipid, the $\mathrm{Ca}^{++}$ is apparently adsorbed to the micelles $(21,22)$, and one could postulate that the $\mathrm{Ca}^{++}$then acts to bind the micelles to negatively charged groups on the membranes. This explanation seems somewhat less probable in the case of cerebroside binding, and it also does not explain the effect of the monovalent ions. Perhaps the ions, of all types, act by changing the charge distribution on the membrane surfaces, causing a configurational change which favors lipid binding (as by bringing lipophilic groups out to the surface). It is well known that divalent ions affect the swelling of mitochondria, with a consequent change in membrane structure, and it is possible that myelin reacts similarly.
This interpretation is supported by an experiment with labeled $\mathrm{Ca}^{++}$, in which we incubated myelin $(0.6 \mathrm{mg}$ protein) with $4 \mu$ moles of $\mathrm{CaCl}_{2}$ in the usual way. The uptake of $\mathrm{Ca}^{++}$ was $0.057 \mu$ atoms, a value in good agreement with the concentration of total divalent ions found in myelin preparations by Gerstl et al. (23). Apparently most or all of the divalent metal ions in our preparation exchanged with the aqueous $\mathrm{Ca}^{++}$. (This bound $\mathrm{Ca}^{++}$could be removed by incubation with unlabeled $\mathrm{Ca}^{++}$.) When lecithin emulsions were added to the ${ }^{45} \mathrm{Ca}$ and myelin, the amount of $\mathrm{Ca}^{++}$uptake was not noticeably affected. It may be concluded that the configurational change in the membrane induced by the surrounding ions is not the result of a strong linkage, and that the membrane-lipid complex, once formed, loses its surrounding ions during the washing step without uncoupling of the membrane-lipid linkage. However, the sensitivity of this experiment depends on how much $\mathrm{Ca}^{++}$is required for the binding. In the lecithin experiment, about $0.06 \mu$ moles of lecithin was taken up. If the lecithin particles were bound mole-for-mole with labeled $\mathrm{CaCl}_{2}$, the observed uptake of $\mathrm{Ca}^{++}$would be 0.06 atoms above the control value. The experimental procedure would detect an uptake of $1 / 10$ this amount, so the molar ratio of $\mathrm{Ca}^{++}$to lecithin in the micelles could be $1: 10$ or less.

\section{Effect of Membrane Delipidation}

Samples of myelin and mitochondria were partially delipidated with acetone (final concentration about $85 \%$ ) and compared with unprocessed particles. The relationship between uptake of lecithin and $\mathrm{Ca}^{++}$concentration is shown in Fig. 1. It can be seen that normal myelin is more effective than mitochondria in taking up lecithin (per milligram of protein), perhaps due to its higher lipid content. The same relationship is seen with the lipid-depleted membranes, which take up somewhat less lecithin. This reduced uptake is consistent with the above idea, that uptake is due primarily to the lipid portion of the membrane surfaces.

In all four systems, $\mathrm{Ca}^{++}$greatly increases the amount of uptake. At higher levels of $\mathrm{Ca}^{++}$ there is reduced effectiveness; perhaps this means that $\mathrm{Ca}^{++}$becomes attached to the lecithin micelles at the higher concentrations and such micelles are not as readily taken up by the membranes.

A similar comparison with cerebroside and cholesterol is shown in Table II. It is evident 


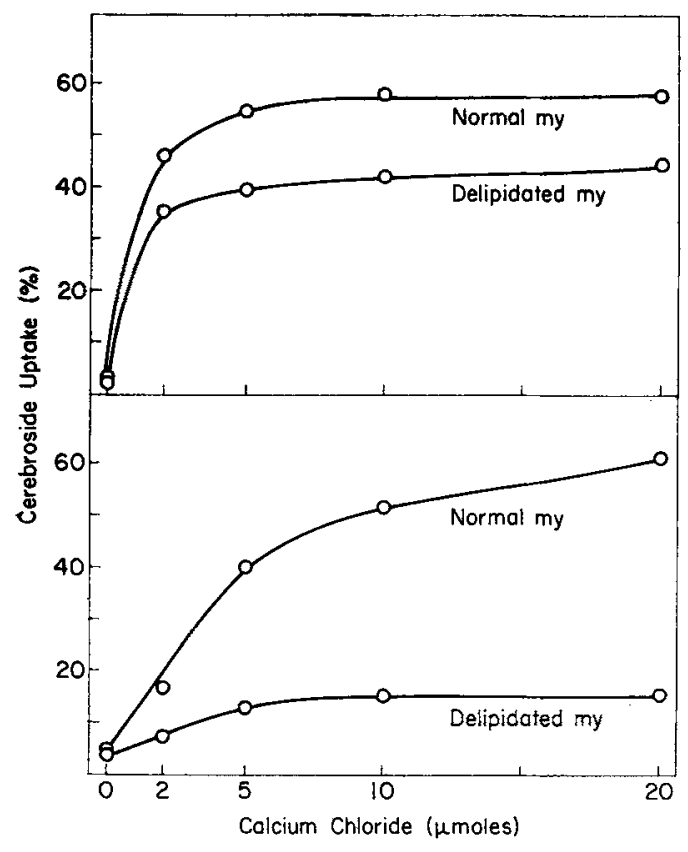

FiG. 3. Uptake of cerebroside emulsions by myelin and lipid-depleted myelin. Upper curves: $20 \mu \mathrm{g}$ cerebroside $+60 \mu \mathrm{g}$ detergent $+100 \mu \mathrm{g}$ lecithin. Lower curves: same, but without lecithin.

that both normal mitochondria and myelin take up cerebroside, but that myelin is much more effective (see also Figs. 4 and 5). In this sense, cerebroside could be considered as being more specifically bound to myelin than to mitochondria, which contain little cerebroside $(24,25)$. Cholesterol also shows preferential uptake by myelin, but not as specifically. The effect of lipid depletion, as with lecithin, was a marked decrease in lipid uptake by both types of cell particles. The delipidation effect was markedly greater with increased $\mathrm{Ca}^{++}$levels and was somewhat greater for cerebroside than for lecithin. As noted before, cholesterol uptake was not affected by calcium.

The uptake of cerebroside by delipidated myelin could be appreciably enhanced by incorporating lecithin into the cerebroside-detergent micelle (Fig. 3). (The mixed micelle was made by evaporating all three compounds from organic solvent and emulsifying them simultaneously.) With normal myelin, lecithin acted to enhance cerebroside uptake at low levels of $\mathrm{Ca}^{++}$, but there seemed to be little effect at high levels. With depleted myelin, there was a marked enhancement at all levels. Since we have shown that lecithin is more

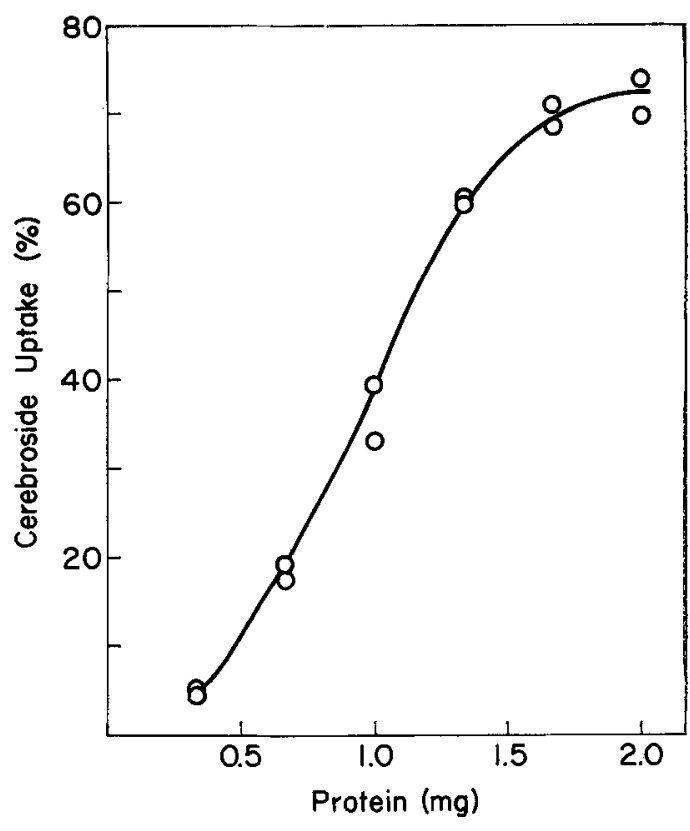

FIG. 4. Dependence of cerebroside uptake on quantity of mitochondria. Tubes contained $20 \mu \mathrm{g}$ cerebroside $+40 \mu \mathrm{g}$ detergent $+20 \mu$ moles calcium chloride.

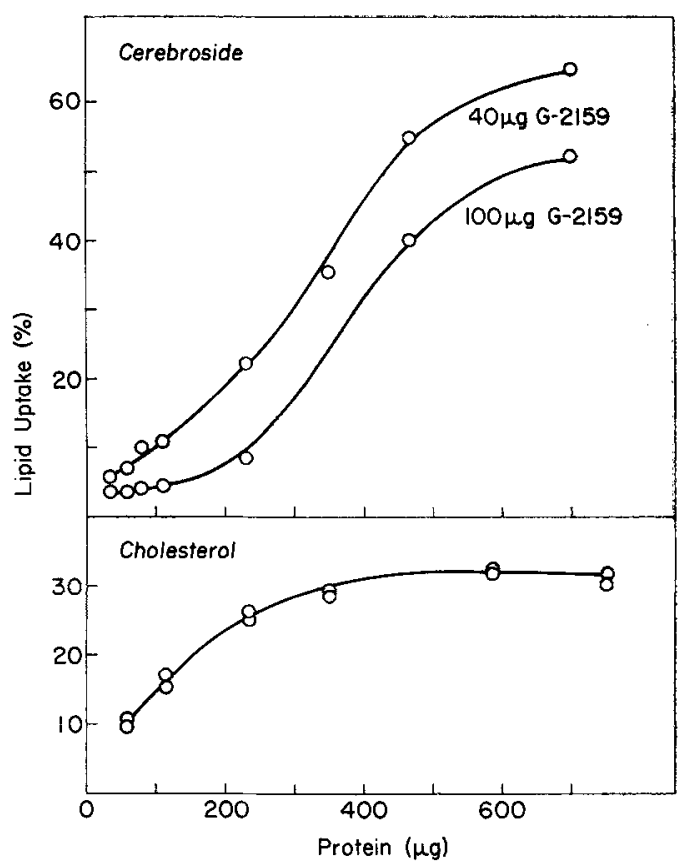

FIG. 5. Uptake of lipids by increasing amounts of myelin, and effect of additional detergent. Upper curves: $20 \mu \mathrm{g}$ cerebroside +40 or $100 \mu \mathrm{g}$ detergent. Lower curve: $10 \mu \mathrm{g}$ cholesterol +1 mg detergent. Tubes contained $5 \mu$ moles $\mathrm{CaCl}_{2}$. 
TABLE III

Composition of Lipids Taken up by Myelin from Lecithin-Cerebroside Mixtures

\begin{tabular}{|c|c|c|c|c|c|c|c|}
\hline \multirow[b]{3}{*}{$\begin{array}{c}\text { Experiment } \\
\text { number }\end{array}$} & \multirow{3}{*}{$\begin{array}{c}\text { Amount } \\
\text { of Ca++ } \\
\text { ( } \mu \text { atoms) }\end{array}$} & \multicolumn{6}{|c|}{ Weight of lipids (in $\mu \mathrm{g}$ ) } \\
\hline & & \multicolumn{3}{|c|}{ Initial emulsion } & \multicolumn{3}{|c|}{ Taken up by myelin } \\
\hline & & Lecithin & $\begin{array}{c}\text { Cere- } \\
\text { broside }\end{array}$ & $\mathrm{L} / \mathrm{C}$ & Lecithin & $\begin{array}{c}\text { Cere- } \\
\text { broside }\end{array}$ & $\mathrm{L} / \mathrm{C}$ \\
\hline $\begin{array}{l}1 \\
2 \\
3\end{array}$ & $\begin{array}{r}0 \\
2 \\
10\end{array}$ & $\begin{array}{l}1840 \\
1840 \\
1840\end{array}$ & $\begin{array}{l}20 \\
20 \\
20\end{array}$ & $\begin{array}{l}92 \\
92 \\
92\end{array}$ & $\begin{array}{r}7 \\
187 \\
222\end{array}$ & $\begin{array}{l}0.15 \\
2.10 \\
2.52\end{array}$ & $\begin{array}{l}48 \\
89 \\
88\end{array}$ \\
\hline $\begin{array}{l}4 \\
5 \\
6\end{array}$ & $\begin{array}{r}0 \\
2 \\
10\end{array}$ & $\begin{array}{l}500 \\
500 \\
500\end{array}$ & $\begin{array}{l}20 \\
20 \\
20\end{array}$ & $\begin{array}{l}25 \\
25 \\
25\end{array}$ & $\begin{array}{r}6 \\
76 \\
105\end{array}$ & $\begin{array}{l}0.22 \\
3.39 \\
4.20\end{array}$ & $\begin{array}{l}30 \\
23 \\
25\end{array}$ \\
\hline $\begin{array}{l}7 \\
8 \\
9\end{array}$ & $\begin{array}{r}0 \\
2 \\
10\end{array}$ & $\begin{array}{l}256 \\
256 \\
256\end{array}$ & $\begin{array}{l}20 \\
20 \\
20\end{array}$ & $\begin{array}{l}12.8 \\
12.8 \\
12.8\end{array}$ & $\begin{array}{r}4 \\
47 \\
46\end{array}$ & $\begin{array}{l}0.81 \\
9.49 \\
9.22\end{array}$ & $\begin{array}{l}5.3 \\
5.0 \\
5.1\end{array}$ \\
\hline
\end{tabular}

$\mathrm{L} / \mathrm{C}=$ ratio of weights, lecithin: cerebroside.

Incubation conditions: myelin equivalent to $600 \mu \mathrm{g}$ protein; $60 \mu \mathrm{g}$ of detergent in each; $1 \mathrm{ml}$ total volume; incubated $10 \mathrm{~min}$ at $37 \mathrm{C}$.

strongly attracted to delipidated myelin than is cerebroside, apparently the lecithin in the mixed micelle is simply carrying the cerebroside along with it.

To test this explanation, we prepared mixed micelles containing different ratios of lecithin: cerebroside and determined the uptake of both labeled lipids with normal myelin (Table III). Looking at the data obtained from incubations which contained $\mathrm{Ca}^{++}$and higher amounts of lecithin (Experiments 2,3,5, and 6), we see that the ratio of lipids complexing with the myelin was the same as the ratio in the original emulsion. Thus, under these conditions the micelles were taken up by the membrane in toto, as predicted by the above suggestion that the cerebroside simply accompanied the lecithin. In the case of the emulsions containing a low amount of lecithin (Experiments 7-9), the ratio of incorporated lipids is unexpectedly low and independent of $\mathrm{Ca}^{++}$concentration.

It is interesting that the total weight of cerebroside taken up decreased with increasing lecithin content in the emulsion. This is probably not an inhibitory or competitive effect, but simply a reflection of the finite capacity of the myelin portions to take up lipid.

Lecithin could be shown to enhance cerebroside uptake into delipidated myelin by a different mechanism. Depleted myelin was incubated in the usual way with $2 \mathrm{mg}$ of lecithin and $20 \mu$ moles of $\mathrm{CaCl}_{2}$ for $10 \mathrm{~min}$, then washed twice. On subsequent incubation with cerebroside-detergent emulsion and $20 \mu$ moles $\mathrm{Ca}^{++}$, the myelin took up $25 \%$ of the cerebroside. If the $\mathrm{Ca}^{++}$or the lecithin was omitted from the preincubation step, only $10 \%$ of the cerebroside was taken up in the second incubation. This increase in cerebroside uptake is apparently due to the partial relipidation of the myelin by preincubation with the complete system (lecithin + calcium).

The uptake enhancement by phospholipid could be demonstrated also for cholesterol and mitochondria (Table IV). The data on the right

TABLE IV

Uptake of Cholesterol from Phospholipid and Detergent Emulsions by Normal and Delipidated Mitochondria

\begin{tabular}{|c|c|c|c|c|c|c|}
\hline \multirow{3}{*}{$\frac{\begin{array}{c}\text { Amounta of } \\
\text { mitochondria }\end{array}}{(\mathrm{mg})}$} & \multicolumn{4}{|c|}{ Cholesterol + Phospholipid } & \multirow{2}{*}{\multicolumn{2}{|c|}{$\begin{array}{c}\text { Cholesterol + Detergent } \\
\begin{array}{c}\text { Delipidated } \\
\text { mitochondria }\end{array}\end{array}$}} \\
\hline & \multicolumn{2}{|c|}{$\begin{array}{l}\text { Normal } \\
\text { mitochondria }\end{array}$} & \multicolumn{2}{|c|}{$\begin{array}{l}\text { Delipidated } \\
\text { mitochondria }\end{array}$} & & \\
\hline & $\left(-\mathrm{Ca}^{++}\right)$ & $\left(+\mathrm{Ca}^{++}\right)$ & $\left(-\mathrm{Ca}^{+\dot{+}}\right)$ & $\left(+\mathrm{Ca}^{++}\right)$ & $\left(-\mathrm{Ca}^{++}\right)$ & $\left(+\mathrm{Ca}^{++}\right)$ \\
\hline 0.2 & 3.0 & 28 & 2.2 & 19 & 3.7 & 3.6 \\
\hline 0.4 & 4.5 & 36 & ....... & ...... & ....... & ...... \\
\hline 0.6 & 4.8 & 40 & 3.5 & 39 & 8.3 & 8.3 \\
\hline 0.8 & 5.1 & 47 & 4.0 & 36 & 10.9 & 10.2 \\
\hline 1.0 & 4.7 & 49 & 4.7 & 40 & 12.5 & 12.0 \\
\hline
\end{tabular}

- Weight of mitochondrial protein.

All tubes contained $10 \mu \mathrm{g}$ cholesterol, emulsified with $100 \mu \mathrm{g}$ phospholipid or $1 \mathrm{mg}$ detergent. Calcium chloride concentration, where added, was $20 \mathrm{mM}$. Data are percentage of cholesterol taken up by the particles.

LIPIDS, VoL. 3, No. 5 
side of the table illustrate for lipid-depleted mitochondria the same lack of dependency on the presence of $\mathrm{Ca}^{++}$noted before. The data for emulsions made with egg phospholipids and cholesterol show less uptake of cholesterol in the absence of $\mathrm{Ca}^{++}$but considerably increased uptake in the presence of $20 \mu$ atoms of $\mathrm{Ca}^{++}$. Both the enhancement and $\mathrm{Ca}^{++}$effects were presumably mediated through the phospholipid portion of the micelles, and the cholesterol was simply carried along like the cerebroside.

\section{Capacity of Membranes}

The amount of lipid taken up was compared with different amounts of membranous particles. Fig. 4 shows the relationship between cerebroside and mitochondria. The uptake was rather linear over most of the range studied, but leveled off at about $70 \%$ uptake. This failure to take up all of the emulsified lipid may mean that about $30 \%$ of the micelles were of a size which could not be taken up by the mitochondria. The plausibility of this explanation is supported by the finding that groups of particles of two distinct sizes can readily be produced in simple lipid emulsions (26-28).

A similar situation was seen with myelin and cerebroside and cholesterol (Fig. 5). Here too the maximal cerebroside uptake was in the neighborhood of $70 \%$, so the two membranes did not seem to differ with respect to the types of micelles that could be taken up. Cholesterol leveled off at $30 \%$ of the incubated lipid. In the case of mitochondria, a mixed phospholipid-cholesterol emulsion was seen to level off at a higher percentage, about 50\% (Table IV, left side). Delipidated mitochondria apparently accepted a smaller range of micelles (about $39 \%)$.

The temperature-dependency experiment shown in Fig. 2 seemed to show that myelin might have a lower capacity for cerebroside at a low temperature. However, further work showed that the uptake is simply slower; after $3 \mathrm{hr}$ at $\mathrm{OC}$ the uptake had nearly leveled off at about $60 \%$. Time studies at $37 \mathrm{C}$ showed uptake leveled off around $15 \mathrm{~min}$ but became erratic with longer periods, evidently owing to progressive breakup of the myelin. Cholesterol uptake by myelin at $37 \mathrm{C}$ leveled off at $10 \mathrm{~min}$.

The amount of cerebroside taken up by mitochondria equivalent to $1 \mathrm{mg}$ of protein was $8 \mu \mathrm{g}$. Assuming the lipid:protein ratio for brain mitochondria is 0.6 (29), the ratio of cerebroside to mitochondrial lipid is $13 \mu \mathrm{g} / \mathrm{mg}$. The corresponding calculation for myelin yields an uptake of $7 \mu \mathrm{g} / \mathrm{mg}$ myelin lipid (assuming myelin is $25 \%$ protein and $75 \%$ lipid).

\section{Detergent Effects}

In Fig. 5 may be seen the effect of increasing the amount of detergent in the cerebroside emulsion. At all levels of myelin there was decreased uptake. With $1 \mathrm{mg}$ of detergent there was no uptake at all. The same interference was seen when $\mathrm{NaCl}$ was used instead of $\mathrm{CaCl}_{2}$, suggesting the detergent did not act by binding $\mathrm{Ca}^{++}$. It should be noted that the cholesterol incubations contained $1 \mathrm{mg}$ of detergent, yet appreciable lipid was taken up. This difference is undoubtedly related to the fact that much more detergent was found necessary to emulsify the cholesterol. Most of the $1 \mathrm{mg}$ of detergent in the cholesterol emulsion must be in the mixed micelle, but most of the $1 \mathrm{mg}$ in the cerebroside emulsion may be in separate micelles of pure detergent. The pure detergent micelles may compete effectively for the lipid binding sites.

The idea that two kinds of detergent molecules can exist in lipid emulsions-free and lipid-bound-and that the free detergent can compete with the lipid micelles for attachment to membranes or enzyme-lipid substrate complexes, might be of general use in lipid biochemistry. It may explain the frequently observed stimulatory action of detergents or bile salts on lipid-acting enzymes, but inhibitory effects when high concentrations of detergents are used. It also may explain, conversely, why cholesterol protects red blood cells against the lytic action of lysolecithin, which is an excellent detergent (30).

A small part of the inhibitory effect of free detergent could be shown to arise from its solubilizing effect on myelin itself. Incubation for $10 \mathrm{~min}$ with $1 \mathrm{mg}$ of detergent, followed by the usual centrifugal washing, was followed by extraction of the lipids in the pellet and supernatant solutions with chloroform-methanol $(2: 1)$. The lipids were quantified by photometric scanning of TLC plates, and it was found that roughly $35 \%$ of the myelin lipids was lost in the washes when no detergent was present, and about $50 \%$ was lost in the detergent incubation. The detergent caused loss of all classes of lipids that were seen on the chromatogram, but ethanolamine phosphoglycerides were lost preferentially. The myelin pellets were not noticeably different in volume.

\section{Nature of the Lipid-Membrane Linkage}

The reversibility of the uptake phenomenon was studied by incubating the washed cerebro- 
TABLE V

Recovery of Myelin Protein After Incubation and Washing

\begin{tabular}{lccc}
\hline & \multicolumn{2}{c}{ Protein in pellet } \\
\cline { 3 - 4 } Incubation medium & $(\mu \mathrm{g})$ & (\% lost) \\
\hline Water alone & & 570,513 & 23 \\
$5 \mu$ atoms Ca++ & 540,530 & 24 \\
40 $\mu$ g detergent & 350,366 & 49 \\
Detergent $+20 \mu$ g cerebroside & 493,450 & 33 \\
Detergent + cerebroside $+\mathrm{Ca}^{++}$ & 563,543 & 21 \\
\hline
\end{tabular}

Protein weights are from duplicate experiments; percentages are averaged.

Incubation conditions: myelin equivalent to $700 \mu \mathrm{g}$ protein, $10 \mathrm{~min}$ at $37 \mathrm{C}$, two washes with $4 \mathrm{ml}$ sucrose solution.

side-myelin complex with a fresh portion of nonradioactive cerebroside-detergent emulsion in $\mathrm{Ca}^{++}$. A decrease in radioactivity of $18 \%$ was observed, but this was equal to the decrease observed in the control incubation (water and $\mathrm{CaCl}_{2}$ alone). Evidently the bound cerebroside cannot readily dissociate or exchange with cerebroside micelles in the medium. An additional incubation with unlabeled cerebroside emulsion resulted in similar additional loss, but a third incubation did not result in further loss. It is likely that part of the myelin (and its attached cerebroside) is more labile to exposure to the incubation medium and breaks off in the form of very small particles, as noted in the experiments on detergent effects.

The loss of myelin during incubation and washing was followed also by measuring the protein portion (Table $\mathrm{V}$ ). It is evident that a small part of the myelin was lost in the procedure and that the detergent alone increased the loss appreciably. However, the detergent that is complexed with cerebroside, especially in the presence of $\mathrm{Ca}^{++}$, had no effect on the loss. This is to be expected from the previous discussion. Centrifugation of the first wash, following incubation, yielded an additional $4 \%$ of the protein in the case of the complete system; with detergent alone, the additional recovery was $12 \%$. This difference presumably represents myelin which had been dissociated by the free detergent, then reaggregated on dilution with the sucrose. Similar reaggregation of membranes solubilized by bile salts has been reported (10).

The lipid uptake is apparently a physical phenomenon, rather than enzymatic. This was indicated by the lack of interference on incubating cerebroside with myelin and puromycin $(5.4 \mu \mathrm{g})$ and iodoacetamide $(200 \mu \mathrm{g})$. Myelin heated $15 \mathrm{~min}$ at $90 \mathrm{C}$ showed considerably bet- ter uptake, $\mathrm{Ca}^{++}$still being required; mitochondria behaved similarly. Uptake was about 92\% with both cell components; evidently the new surface exposed by the heat denaturation was able to adsorb a wider range of emulsion particle sizes.

A similar augmentation was produced in mitochondria by $\mathrm{HgCl}_{2}$ and 2,4-dinitrophenol ( $1 \mu$ mole each), but $\mathrm{Ca}^{++}$reduced the extent of the effect. Mitochondria equivalent to $650 \mu \mathrm{g}$ protein were incubated with cerebroside and $20 \mu$ moles $\mathrm{CaCl}_{2}$; the uptake was $17 \%$. In the presence of $\mathrm{Hg}^{++}$and DNP, the uptakes were $34 \%$ and $55 \%$ respectively; if $\mathrm{Ca}^{++}$was omitted, the uptakes were $92 \%$ and $85 \%$ respectively.

\section{GENERAL DISCUSSION}

\section{The Significance of Particle Size in Emulsions}

We have shown that our lipid emulsions cannot be taken up completely by brain membranes and have suggested that only emulsified particles within a certain range of sizes can be effective. We also noted that excessive amounts of detergent, which may be expected to produce smaller lipid particles, interfere with the uptake process. It is therefore likely that the inactive lipid particles are the smaller ones. The smaller particles presumably contain a relatively high ratio of detergent to lipid; if detergent molecules were taken up preferentially one would predict that these smaller particles would be taken up in preference to the larger ones. This inconsistency suggests that the interfering effect of high detergent concentrations is not due to competitive uptake of detergent, as suggested in the section on detergent effects, but to production of particles that are too small.

It seems clear that work with lipid emulsions will have to take into consideration the factor of particle size, and the effect of additives of various sorts (lipoidal and nonlipoidal) on the particle size of the emulsion. This problem is relevant not only to in vitro enzyme work but to physiological matters, such as the tendency of circulating lipids to be taken up by organs and arterial walls. The phenomenon of the stabilizing or labilizing action of lipids on lysosomes and circulating blood cells may involve uptake of emulsion particles of specific sizes.

\section{The Self-Assembly of Membranes}

Our findings are consistent with the idea that membranes are formed, in part at least, by a self-assembling process. Some evidence for

LiPIDS, Vol. 3, No. 5 
specificity of assembly was obtained; we found lecithin to be taken up more efficiently than cerebroside or cholesterol, especially by lipiddepleted membranes. The uptake of cerebroside by mitochondria might seem a sign of nonspecificity, as the cerebroside content of some mitochondrial preparations has been found to be low (25) and might actually represent some contamination by myelin.

It is now well known that cerebroside deposition in brain does not become appreciable until myelin deposition begins on a vigorous scale. In rats this is about 10 days of age (9). Lecithin deposition is already quite active before this time and it is tempting to think, drawing upon our findings on relipidation with lecithin, that cerebroside deposition cannot begin until lecithin first condenses with myelin protein. In agreement with this concept are the reports $(6,7)$ indicating that myelin from young mice and rats is relatively rich in lecithin, but low in cerebroside and cholesterol.

Since myelin lipids undergo attrition by some process of turnover (25), there must be some mechanism for replacing the lipid molecules. Perhaps the mechanism involves an uptake process similar to those observed in this study. It is unlikely that myelin is destroyed and replaced in toto as the component lipids are destroyed at different rates. If myelin (and other membranous particles) lose their component lipids from assorted regions, the membranes isolated from animals at any moment of life must have regions that are deficient in lipids. Presumably these are the sites which took up lipids in our incubation experiments.

In agreement with this viewpoint is the finding by Omura et al. (31) that the lipids of liver microsomes exhibit a turnover rate that is higher than that of the microsomal proteins. Thus, there must always be some empty sites available for uptake of new lipid molecules.

Some recent studies with whole membranes, their disaggregation, and their reaggregation indicate that membrane components can be reassembled into a complex much like the original one. The cell membranes of a microorganism have been disaggregated with anionic detergents, then dialyzed until the membrane reformed (32). It was necessary to dialyze against $0.01 \mathrm{M} \mathrm{Ca}^{++}$or $\mathrm{Mg}^{++}$, a concentration we found quite effective for lipid uptake. The reformed membrane was a little thinner than the original membrane but showed the same triple-layer pattern. The reformed membrane had a lower protein content than the original, possibly because the composition of the final product depends on the proportions of the components in the "soluble" form.

Of particular interest is the study by Pollack et al. (4) in which it was shown that liver reticulosomes (minute particles occurring in the microsomal fraction) could take up lipids from a crude phospholipid emulsion. Electron microscopy revealed conversion of the particles to membranous particles and the authors hypothesized that the reticulosomes are the precursors of membranes. They are visible best during the period of most active growth, presumably because lipid synthesis does not quite keep pace with the reticulosomal protein synthesis. Thus the reticulosomes, once they have combined with lipid, could be considered as "protomembranes" which are transported and assembled into the larger membranes of specialized structures.

Some evidence for such a process in brain comes from a study we made of the fatty acid distribution in lipids from different brain particles (33). The acids of sphingomyelin and cephalins (ethanolamine and serine lipids) were examined. It was found that the distribution of acids was very similar in synaptosomes (nerve terminals) and microsomes of gray matter. Myelin had a considerably different pattern, and the microsomes from white matter had a pattern intermediate between those of myelin and gray microsomes. These results indicate that microsomes have a characteristic composition, whether from gray or white matter, but they also include "protomembrane" particles characteristic of adjoining membranes. Thus, white microsomes include "protomyelin" fragments and gray microsomes include "protosynaptosomes"; these particles are in the process of being transported to the zones where they will be assembled into place.

\section{Comparison with Other Lipid Uptake Studies}

Cholesterol uptake by L5178Y tissue-culture cells showed several points of similarity (34). The cholesterol, once taken up, was not removable by exchange. Delipidation impaired sterol uptake, but the effect of relipidation was not studied. Heated cells (60C for $30 \mathrm{~min}$ ) were also as effective as normal cells. It is interesting that uptake was observed when horse serum was used to emulsify the cholesterol, as well as when a non-ionic detergent was used.

Another study demonstrated palmitic acid uptake by mitochondria and microsomes (1). Here the lipid was kept in solution by complexing with serum albumin, so it would appear 
that the particle size was much lower than in our emulsions. The uptake was not much less at $0 \mathrm{C}$ than at $37 \mathrm{C}$ and it leveled off after about 10-30 min. In this and the above study the particles were suspended in salt-containing medium, so the influence of cation concentration was not investigated.

It is obvious that the conditions used in these and our uptake studies were far from physiological and the various proposals must be considered highly tentative.

\section{ACKNOWLEDGMENTS}

We are greatly indebted to Dr. Otto $Z$. Sellinger for the enzyme assays. Miss Elena Benvenuto skillfully assisted in the study. This study was supported in part by USPHS grant NB 03192 from the National Institute of Neurological Diseases and Blindness.

\section{REFERENCES}

1. Reshef, L., and B. Shapiro, Biochim. Biophys, Acta 98, 73-80 (1965).

2. Wolfe, L. S., Biochem. J. 79, 348-355 (1961).

3. Graham, J. M., and C. Green, Biochem. J. 104, 24P (1967).

4. Pollak, J. K., K. Ward and C. D. Shorey, J. Mol. Biol. 16, 564-567 (1966).

5. Fleischer, S., G. Brierley, H. Klouwen and D. B. Slautterback, J. Biol. Chem. 237, 3264-3272 (1962).

6. Cuzner, M. L., and A. N. Davison, Biochem. J. 106, 29-34 (1968).

7. Horrocks, L. A., R. J. Meckler and R. L. Collins, in "Variation in Chemical Composition of the Nervous System," G. B. Ansell, ed., Pergamon Press, Oxford, 1966, p. 46.

8. Kishimoto, Y., and N. S. Radin, J. Lipid Res. 1, 79-82 (1959).

9. Kishimoto, Y., W. E. Davies and N. S. Radin, J. Lipid Res. 6, 532-536 (1965).

10. Green, D. E., D. W. Allmann, E. Bachmann, H. Baum, K. Kopaczyk, E. F. Korman, S. Lipton, D. H. MacLennan, D. G. McConnell, J. F. Perdue, J. S. Rieske and A. Tzagoloff, Arch. Biochem. Biophys. 119, 312-335 (1967).

11. Autilio, L. A., W. T. Norton and R. D. Terry, J. Neurochem. 11, 17-27 (1964).
12. Arnaiz, G. R. de L., M. Alberici and E. de Robertis, J. Neurochem. 14, 215-225 (1967).

13. Sellinger, O. Z., and R. A. Hiatt, Brain Res., Vol. 7, p. 191-200 (1968).

14. Lamar, C., Jr., and $O$. Z. Sellinger, Biochem. Pharm. 14, 489-506 (1965).

15. Bruno, G. A., and J. E. Christian, Anal. Chem. 33, 1216-1218 (1961).

16. Bowen, D. M.. and N. S. Radin, Biochim. Biophys. Acta $152,587-598$ (1968).

17. Dobiasova, M. and P. Hahn, Physiol. Bohem., in press.

18. Ansell, G. B. and J. N. Hawthorne, "Phospholipids," Elsevier Publ. Co., Amsterdam, 1964, p. 99.

19. Lowry, O. H., N. J. Rosebrough, A. L. Farr and R. J. Randall, J. Biol. Chem. 193, 265-275 (1951).

20. Lester, R. L., and S. Fleischer, Biochim. Biophys. Acta 47, 358-377 (1961).

21. Thomas, I. L., J. Pharm. Pharmacol. 14, 456-463 (1962).

22. Bangham, A. D., and R. M. C. Dawson, Biochim. Biophys. Acta 59, 103-115 (1962).

23. Gerstl, B., L. F. Eng, R. B. Hayman, M. G. Tavaststjerna and P. R. Bond, J. Neurochem. 14, 661-670 (1967).

24. Eichberg, J., Jr., V. P. Whittaker and R. M. C. Dawson, Biochem. J. 92, 91-100 (1964).

25. Smith, M. E., and L. F. Eng, JAOCS 42, 1013-1018 (1965).

26. Feldman, E. B., and B. Borgström, Lipids 1, 430438 (1966).

27. Borgström, B., J. Lipid Res. 8, 598-608 (1967).

28. Feldman, E. B., and B. Borgström, Biochim. Biophys. Acta 125, 136-147 (1966).

29. Nussbaum, J. L., and P. Mandel, Bull. Soc. Chim. Biol. 47, 395-408 (1965).

30. Delezenne, C., and E. Fourneau, Bull. Soc. Chim. 15, 421-434 (1914).

31. Omura, T., P. Siekevitz and G. E. Palade, J. Biol. Chem. 242, 2389-2396 (1967).

32. Razin, S., H. J. Morowitz and T. M. Terry, Proc. Nat. Acad. Sci., U. S. 54, 219-225 (1965).

33. Radin, N. S., Y. Kishimoto, B. W. Agranoff and R. M. Burton, Fed. Proc. 26, 676 (1967).

34. Rothblat, G. H., R. W. Hartzell, Jr., H. Mialhe and D. Kritchevsky, Biochim. Biophys. Acta 116, 133-145 (1966).

[Received Jan. 17, 1968] 